\title{
Mixoma cardíaco y enfermedad coronaria en paciente octogenario*
}

\author{
Drs. ROBERTO GONZÁLEZ L. ${ }^{1}$, JUAN FARÍAS M. ${ }^{1}$, ENRIQUE SEGUEL S. ${ }^{1}$, ALECK STOCKINS L. ${ }^{1}$, \\ RODRIGO ÁlVAREZ L. ${ }^{2}$, LUIS NEIRA S. ${ }^{1}$, CAROLINA DELGADO SCH. ${ }^{3}$, EMILIO ALARCÓN C. ${ }^{1}$
}

Hospital Dr. Guillermo Grant Benavente, Facultad de Medicina, Universidad de Concepción, Concepción, Chile.

1 Equipo de Cirugía Cardiotorácica.

2 Sección de Cardiología.

3 Anatomía Patológica.

\section{Cardiac myxoma with coronary artery disease}

Hombre de 80 años con antecedentes de hipertensión arterial y enfermedad pulmonar obstructiva crónica. Consultó por disnea y angina progresiva de un año de evolución. El ecocardiograma demostró una masa tumoral de 5 por 3 centímetros en la aurícula izquierda, móvil, pediculada y que protruye a través de la válvula mitral hacia ventrículo izquierdo (Figura 1A). La masa tumoral tenía base de im- plantación en el tabique inter auricular y era compatible con mixoma.

Se completó el estudio con coronariografía que demostró enfermedad coronaria; presentaba una lesión crítica en la arteria coronaria descendente anterior y oclusión de la arteria coronaria derecha. En la coronariografía la masa tumoral se contrastaba en forma espontánea (Figuras 1B y 1C).

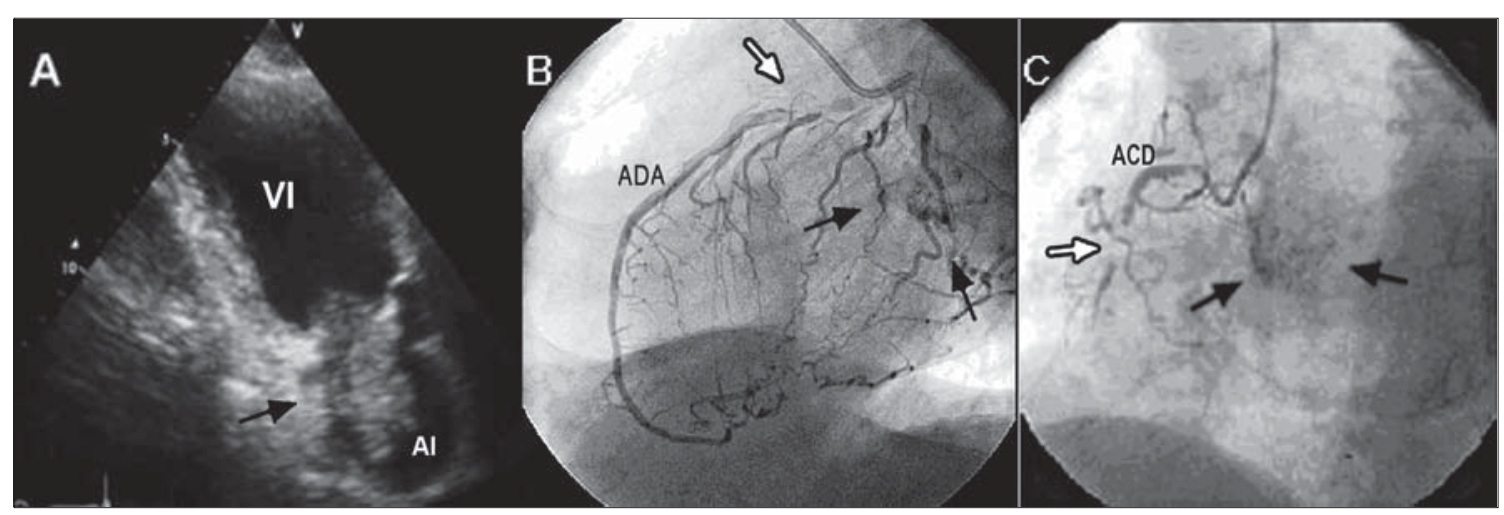

Figura 1. A. Ecocardiografía que muestra masa que protruye a través de la válvula mitral hacia ventrículo izquierdo (Flecha). B y C. Coronariografía que muestra lesiones coronarias (Flechas blancas) y masa tumoral móvil contrastada en aurícula izquierda (Flechas negras). (VI: Ventrículo izquierdo; AI: Aurícula izquierda; ADA: Arteria coronaria descendente anterior; ACD: Arteria coronaria derecha).

\footnotetext{
*Recibido el 6 de Octubre de 2008 y aceptado para publicación el 12 de Enero de 2009.

Correspondencia: Dr. Roberto González L.

Janequeo esquina Chacabuco, Concepción, Chile. Fax: 56-41-2204881

E-mail: rgonzalezlagos@udec.cl
} 


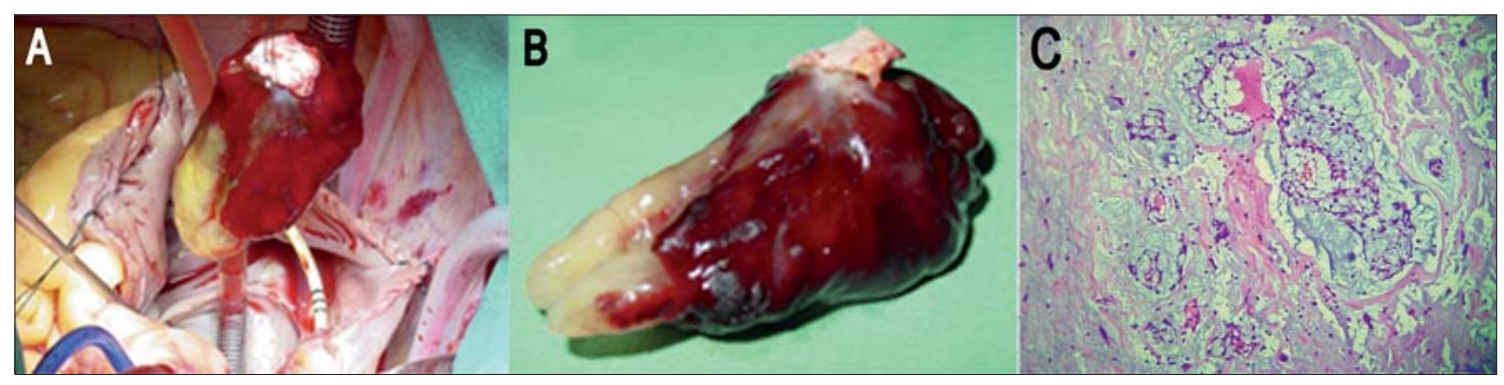

Figura 2. A. Fotografía intra operatoria al momento de la exéresis tumoral. B. Fotografía del tumor resecado. C. Estudio de anatomía patológica con tinción de Hematoxilina-Eosina concluyó mixoma (40X).

En circulación extracorpórea se realizó cirugía de revascularización miocárdica con dos bypass aortocoronarios y exéresis del tumor (Figuras 2A y 2B). El estudio histopatológico concluyó mixoma (Figura 2C).

Los tumores cardíacos primarios son infrecuentes y los mixomas auriculares izquierdos constituyen el grupo más habitual ${ }^{1-3}$. La asociación entre mixoma auricular y enfermedad coronaria ha sido pocas veces reportada ${ }^{4-5}$. Este caso corresponde al primero operado en nuestro grupo, en el que se realizó exéresis tumoral asociando cirugía de revascularización miocárdica.

\section{Referencias}

1. Burke A, Jeudy J, Virmani R. Cardiac tumors: an update.
Heart 2008; 94: 117-123.

2. González R, Raffo M, Alarcón E, Gyhra A, Saldías R, Stockins A, y col. Tumores cardíacos. Rev Chil Cir 2005; 57: 195-198.

3. Becker P, Ramírez A, Zalaquett R, Morán S, Irarrázaval MJ, Arretz C, y col. Mixoma cardíaco: caracterización clínica, métodos diagnósticos y resultados alejados del tratamiento quirúrgico durante tres décadas. Rev Méd Chile 2008; 136: 287-295.

4. Erdil N, Ates S, Cetin L, Demirkilic U, Sener E, Tatar H. Frequency of left atrial myxoma with concomitant coronary artery disease. Surg Today 2003; 33: 328-331.

5. Gismondi RA, Kaufman R, Correa GA, Nascimento C, Weitzel LH, Reis JO, et al. Left atrial myxoma associated with obstructive coronary artery disease. Arq Bras Cardiol 2007; 88: 1-3. 